\title{
AJARAN KESUSILAAN \\ DALAM GAGURITAN DHARMA PRAWERTI
}

\author{
Oleh: Putu Sanjaya ${ }^{1}$
}

\begin{abstract}
Gaguritan Prawerti Dharma is a literary work that contains the teachings of the Hindu religious morals namely Dasa Sila, Mala Tri, Tri Yadnya, Catur Prawerti, Catur Varna, Catur Paramitha, Sad Varga, Tri Parartha, and Daiwi and Asuri Sampad. The Hinduism contained in Gaguritan Prawerti Dharma teaches that every person should always make the moral teachings as a guide in any behavior that could be realized life in safety and peace. In addition Gaguritan Prawerti Dharma should teach humans which in this case is the Hindus, to be able to refrain from any wild desire. Gaguritan Dharma Prawerti containing Dharma teachings of morality really appropriate and relevant when used as a guideline for behavior. Current state of society who tend to behave the hedonistic, consumerist, materialistic, and pragmatic, if not matched by affirmation teachings of morality in every individual would bring the society to destruction and chaos. Thus why the moral teachings in life should always be upheld.
\end{abstract}

Key word: Gaguritan Prawerti Dharma, Morals

\begin{abstract}
Abstrak
Gaguritan Dharma Prawerti merupakan sebuah karya sastra yang mengandung ajaran-ajaran kesusilaan agama Hindu yakni Dasa Sila, Tri Mala, Tri Yadnya, Catur Prawerti, Catur Warna, Catur Paramitha, Sad Warga, Tri Parartha, serta Daiwi dan Asuri Sampad.Ajaran kesusilaan agama Hindu yang termuat dalam Gaguritan Dharma Prawerti mengajarkan kepada setiap orang agar hendaknya senantiasa menjadikan ajaran-ajaran kesusilaan itu sebagai pedoman dalam setiap perilakunya sehingga dapat diwujudkan kehidupan yang aman tenteram dan damai. Selain itu Gaguritan Dharma Prawerti mengajarkan hendaknya manusia yang dalam hal ini adalah umat Hindu, untuk bisa mengendalikan diri dari setiap keinginan yang liar. Gaguritan Dharma Prawerti yang berisikan ajaran-ajaran kesusilaan sungguh tepat dan relevan apabila digunakan sebagai sebuah pedoman dalam berperilaku. Kondisi masyarakat saat ini yang cenderung berperilaku hedonis, konsumtif, materialistis, dan pragmatis, bila tidak diimbangi dengan peneguhan ajaranajaran kesusilaan dalam diri setiap individu akan membawa masyarakat itu pada kehancuran dan kekacauan. Demikian sebabnya ajaran susila dalam kehidupan harus selalu ditegakkan.
\end{abstract}

\section{Kata Kunci: Geguritan Dharma Prawerti, Susila}

${ }^{1}$.I Putu Sanjaya, S.Ag.,M.Pd.H. dosen pengajar di STAH Mpu Kuturan Singaraja. 


\section{PENDAHULUAN}

Issue degradasi moral atau perilaku menyimpang yang marak terjadi dalam kehidupan seolah mensinyalir bahwasanya tidak adanya responsifitas dari diri peserta didik terhadap pendidikan moral dan pendidikan agama yang diperoleh di bangku sekolah. Pendidikan moral dan pendidikan agama seakan hanya menjadi sebuah kajian teoretis dan konsep bersama guna mencapai angka kelulusan supaya bisa terlepas dari sekolah, dan ketika berada di luar sekolah semua teori dan konsep itu tersimpan sembarangan di gudang belakang otak manusia. Praktik pendidikan khususnya di bidang moral dan agama belum mencapai sasaran yang berarti.

Guna mengatasi degradasi moral dan perilaku menyimpang yang terjadi pada generasi penerus bangsa, khususnya anak-anak, pendidikan moral dan pendidikan agama bukan sebuah bahan yang harus ditinggalkan. Pendidikan agama sebagai salah satu disiplin mata pelajaran telah menjadi bagian dari kurikulum pendidikan di Indonesia sejak lama. Akan tetapi pendidikan agama yang diperoleh siswa di sekolah tidak akan memiliki makna apabila konsep-konsep yang ia peroleh dalam pendidikan agama tersebut tidak diterapkan dalam kehidupansehari-hari.

Krisis moral yang menjadi fenomena dewasa ini merupakan salah satu ciri pengingkaran terhadap ajaran agama. Jalaluddin (2003:123) menjelaskan bahwa orang yang berjiwa sehat dalam beragama memiliki ciri-ciri diantaranya bersifat optimis dan gembira, ekstrovet serta mudah melupakan kesan-kesan buruk dan luka hati, menyenangi teologi yang luwes dan tidak kaku, menekankan ajaran cinta kasih, serta selalu berpandangan positif. Sikap positif dalam beragama tersebut yang diharapkan menjadi landasan anak-anak dalam berperilaku sehingga dapatterwujud suatu kehidupan yang tenteram dan damai.

Sumber belajar untuk Pendidikan Agama Hindu tidak terbatas hanya pada buku-buku yang digunakan dalam pembelajaran di kelas formal, akan tetapi juga bisa dengan menggunakan karya-karya sastra. Salah satu karya sastra yang dapat digunakan adalah karya sastra dalam bentuk gaguritan. Gaguritan merupakan salah satu bentuk karya sastra yang hingga kini masih eksis dan bertahan di kalangan penggemar karya sastra klasik. Hal itu disebabkan karena karya sastra dalam bentuk gaguritan kaya akan petuah-petuah, ajaranajaran, yang bersumber dari kitab suci agama Hindu yaitu Weda. Gaguritan pada umumnya diinterpretasikan pada sebuah pembelajaran nonformal yang disebut dengan Pasantian, melalui sebuah proses yang disebut dengan mabebasan.

Salah satu gaguritan yang banyak diinterpretasikan dan eksis sampai sekarang adalah gaguritan Dharma Prawerti. Adapun gaguritan Dharma Prawerti merupakan sebuah karya sastra yang dikarang oleh seorang pendeta bernama Ida Pedanda Putra Kamenuh, pada tahun 1971. Gaguritan Dharma Prawerti ditampilkan dengan gaya bahasa yang ringan, mudah dipahami, dan sarat dengan ajaran-ajaran agama Hindu terutama di bidang etika berperilaku. Terkait dengan hal itu maka penulis tertarik untuk mengkaji lebih dalam terhadap gaguritan Dharma Prawerti dari sudut pandang pendidikan agama Hindu.

\section{PEMBAHASAN}

Adapun pustaka utama yang dijadikan objek kajian dalam tulisan ini adalah buku Gaguritan Dharma Prawerti karya Ida Pedanda Putra Kamenuh yang diterbitkan oleh toko buku Indra Jaya Singaraja. Gaguritan (menurut Wikipedia.org) berasal dari bahasa Jawa tengahan, berasal dari kata dasar gurit, yang berarti tatahan, coretan. Gaguritan merupakan bentuk puisi yang berkembang di kalangan penutur bahasa Jawa dan Bali. Gaguritan berkembang dari tembang, sehingga dikenal beberapa gaguritan yang berbeda. Dalam bentuk yang awal, gaguritan berwujudnyanyian 
yang memiliki sanjak tertentu. Di Bali berkembang bentuk gaguritan semacam ini. Pengertian gaguritan di Jawa telah berkembang menjadi sinoni dengan puisi bebas, yaitu puisi yang tidak mengikatkan diri pada metrum, sajak, dan lagu. Gaguritan merupakan salah satu penciri sastra Jawa modern yang sangat berkembang, diajarkan di sekolah-sekolah dan kerap dilombakan.

Gaguritan pada dasarnya adalah puisi atau sajak yang mengguanakan bahasa Jawa. Biasanya berisikan tentang pengalaman hidup ataupun kejadian sehari-hari yang ada dalam masyarakat. Makna yang terkandung di dalamnya pun terbilang positif karena berisikan nilai-nilai kehidupan, petuah bijak, nasihat, dan lain-lain. Gaguritan merupakan media halus untuk membentuk watak dan menumbuhkan kebaikan bagi generasi penerus. Dahulu dalam masyarakat Jawa kuno, gaguritan sering kali disampaikan oleh para pujangga atau penyair yang kerap kali dianggap sebagai guru. Masyarakat pun amat menghormati keberadaan para pujangga (http://dbzskybutby blogspot.com/diakses 1 Maret 2013).

Gaguritan Dharma Prawerti merupakan sebuah karya sastra yang berbahasa Bali, yang sarat berisikan ajaran-ajaran agama Hindu. Sebagai sebuah karya sastra yang bernuansa keagamaan, gaguritan Dharma Prawerti sangat penting untuk dikaji lebih mendalam untuk memperoleh pengertahuan dan informasi terkait dengan ajaran-ajaran agama Hindu yang sangat bermanfaat sebagai materi Pendidikan Agama Hindu.

Wiana (1997:68) menjelaskan bahwa pendidikan Agama Hindu di Indonesia melalui tiga jalur yaitu jalur keluarga, jalur sekolah, dan jalur masyarakat. Dalam jalur keluarga peranan orang tua sangat menentukan. Tantangannya adalah apabila orang tua kurang memahami serta tidak mengamalkan ajaran agamanya dengan baik, hal ini sangat mempengaruhi kepribadian sang anak. Teladan dari orang tua sangat menentukan keberhasilanpendidikan agama dalam keluarga. Pada jalur sekolah, pendidikan agama diberikan secara sistematis, terarah, dan sesuai dengan kurikulum serta dididik oleh guru-guru yang berwenang untuk melaksanakan pendidikan Agama Hindu itu sendiri. Tantangan yang dihadapi dalam melaksanakan pendidikan Agama Hindu pada tingkat sekolah dasar, berbeda dengan di tingkat sekolah menengah, apalagi di tingkat sekolah tinggi. Di samping dua jalur tersebut, lingkungan sosial juga ikut menentukan keberhasilan pendidikan agama. Lingkungan masyarakat yang homogen (seagama) akan berbeda dampaknya dengan lingkungan masyarakat yang heterogen (berbeda agama). Oleh karena itu perlu diciptakan kondisi lingkungan sosial yang dapat mendukung keberhasilan pendidikanagama.

Pendidikan Agama Hindu menurut Peraturan Pemerintah No. 55 Tahun 2007 selain dilaksanakan di sekolah juga dapat dilaksanakan di luar sekolah. Tujuannya adalah untuk meningkatkan pengetahuan dan pemahaman ajaran Agama Hindu secara mendalam kepada seluruh umat Hindu. Selain itu hasil penanaman ahlak dan moral dapat diaplikasikan secara nyata oleh peserta didik dalam kehidupan beragama sehari-hari (Tanu, 2008:29). Kesatuan Tafsir Terhadap Aspekaspek Agama Hindu (2000:23) menjelaskan bahwa pendidikan agama Hindu yang diselenggarakan di luar sekolah merupakan suatu upaya untuk membina pertumbuhan jiwa masyarakat dengan ajaran agama Hindu itu sendiri sebagai pokok materi. Lebih lanjut dijelaskan bahwa pendidikan agama Hindu di luar sekolah memiliki tujuan untuk: 1) menanamkan ajaran agama Hindu itu menjadi keyakinan dan landasan segenap kegiatan umat Hindu dalam semua perikehidupannya, 2) mengarahkan pertumbuhan tata kemasyarakatan umat Hindu sehingga serasi dengan dasar negara Indonesia yaitu Pancasila; 3) menyerasikan dan menyeimbangkan pelaksanaan bagian-bagian ajaran agama Hindu 
dalam masyarakat yaitu antara tattwa, susila, dan yadnya, dan 4) untuk mengembangkan kerukunan antar umat beragama.

Berdasarkan uraian tersebut dapatlah ditarik suatu kesimpulan bahwasanya pendidikan agama Hindu adalah suatu usaha pembinaan kepada umat Hindu terutama pembinaan dalam hal mental, moral, dan spiritual yang bertujuan untuk tercapainya citacita pembangunan nasional, tercapainya tujuan pendidikan nasional, dan terlahirnya umat Hindu yang bersradha dan berbhakti kepada Ida Hyang Widhi Wasa, melalui proses pendidikan dan pembinaan yang dapat dilaksanakan dengan berbagai metode dan pendekatan guna terwujudnya masyarakat yang aman, damai, dan sejahtera.

\section{Gaguritan DharmaPrawerti}

\subsection{GambaranUmum}

Adapun latar dari gaguritan Dharma Praweti adalah dialog antara seorang guru spiritual kepada muridnya (sisya). Dalam dialog tersebut sang guru memberikan petuah-petuah kebajikan kepada sang murid. Dalam bahasabahasa sastra gaguritan termasuk juga dalam lontar-lontar, guru juga bisa disebut dengan istilah Nabe, Acarya, ataupun Brahmana, yang pada dasarnya memiliki esesnsi yang sama, yakni sebagai orang yang telah paham benar mengenai pengetahuan-pengetahuan kerohanian termasuk juga ilmu-ilmu tattwa, etika, maupun tentang pelaksanaan upacara.

Pada catatan kaki dalam tulisannya, Punyatmadja (1994:24) menjelaskan bahwa kata Nabe kemungkinan berasal dari kata Tabe, yang asal mulanya berasal dari kata Sansekerta yaitu Ksantawya yang berarti maafkanlah atau maaf dengan penuh hormat. Kemudian kata Ksantawya ini berubah menjadi kata Ksantabya, yang berubah lagi menjadi Santabeya. Selanjutnya mengalami perubahan kembali menjadi Santabe atau Sang Tabe, dan dengan awalan $\mathrm{Pa}$ berubah menjadi
Pasangtabe. Kata Pasangtabe ini sering disebut dengan sebutan Tabe saja. Mungkin kata Tabe ini menjadi kata Tabik. Dalam bahasa Bali kata Tabe ini biasanya diikuti dengan kata Pakulun, sehingga menjadi kata Tabe Pakulun yang artinya maaf dengan sangat hormatku. Berdasarkan uraian tersebut, penulis menyimpulkan bahwa kata Nabe dapat diartikan sebagai ia yang dihormati. Sudah barang tentu dalam proses menuntut ilmu, yang paling patut dihormati adalah sang guru itu sendiri.

Sebutan lain untuk guru adalah Brahmana. Kenapa disebut Brahmana, karena seorang guru adalah ia yang tahu tentang hakekat dan ajaran mengenai Brahman (Tuhan). Brahmana adalah golongan cendekiawan yang mampu menguasai ajaran, pengetahuan, adat, adab hingga keagamaan. Di zaman dahulu, golongan ini umumnya adalah kaum pendeta, agamawan atau brahmin. Brahmana adalah golongan karya yang memiliki kemampuan penguasaan ilmu pengetahuan baik pengetahuan suci maupun pengetahuan ilmiah secara umum. Bakat kelahiran para Brahmana adalah mampu mengendalikan pikiran dan prilaku, menulis dan berbicara yang benar, baik, indah, menyejukkan dan menyenangkan. Kemampuan itu menjadi landasan untuk mensejahterakan masyarakat, negara dan umat manusia dengan jalan mengamalkan ilmu pengetahuannya, menjadi manggala (yang dituakan dan diposisikan secara terhormat), atau dalam keagamaan menjadi pemimpin upacara keagamaan (id.wikipedia.org). Manawa Dharmasastra II.226 menyebutkan bahwa:

Acaryo brahmano murtih pita murtih prajapateh, mata prthiwya murtistu bhrata swo murti atmanah

Terjemahannya:

Guru adalah gambaran dari Brahman, ayah adalah gambaran dari Prajapati, ibu adalah gambaran dari Prthiwi dan kakak adalah gambaran dari diri sendiri. 
Selanjutnya guru juga disebut sebagai Acarya. Di dalam Veda, seseorang yang memberikan pendidikan disebut àcàrya. Nama lainnya adalah "adhyàpaka" yang juga berarti guru, di samping kata "guru" itu sendiri, sedang siswa (perubahan dari kata sisya) disebut Brahmacàri, juga disebut "vidyàrti", yang berarti yang mengejar dan mempelajari ilmu pengetahuan. Àcàrya berarti seseorang yang dianggap tidak hanya memberikan ilmu pengetahuannya secara teoritis kepada para siswa, tetapi juga memperbaiki karakter mereka. Pengertian àcàrya adalah: "àcàraý grahayatìti àcàryaá" yang berarti ia yang memberikan pendidikan karakter (seseorang). Dua hal penting dalam sistem pendidikan menurut Veda adalah brahmacarya dan àcàrya dan melalui kebersamaan keduanya seorang siswa dapat meningkatkan perbaikan moralitas dan karakternya(www.parisada.org).

Selain itu ada juga sebutan Pandita. Kata Pandita dalam teks Sarasamuccaya diartikan sebagai orang yang arif bijaksana. Perilaku arif bijaksana merupakan syarat mutlak yang harus dilaksanakan oleh seorang guru. Sarasamuccaya sloka 409 menjelaskan mengenai diri seorang pandita yaitu:

Kunang ikang buddhi harepharep, ri siddhaning istasadhya, widhiwasa panghilanganterika, titahning widhi ta pwa herakena; yapwan wibhawa, annapana ratna wastradi, bhogapabhoga; si tan karaketan panghilanganterita; kunang ikang sih, si wruh ta ring anityaning sarwabhawa panghilanganterika; yapwan ikang sokasantapadi duhkha, yoga panghilanganterika; yoga ngaranya cittawrttinirodha, kahrtaning manah, sang kumawacaken ika, sira pandita ngaranira.

Terjemahannya:

Adapun pikiran yang sangat mengharapharapkan akan tercapainya keinginan dan niat, maka kekuasaan Tuhan akan merupakan penghapusannya, takdir Tuhan patut dinantikan; akan keinginan terhadap kemewahan, seperti makanan, minuman, permata, pakaian, dan segala macam kenikmatan, adalah tidak melekatnya kehendak hati kepada semuanya itu merupakan alat untuk menghilangkannya; mengenai perasaan terikat cinta kasih, maka keyakinan akan tidak kekalnya segala yang ada (hidup) menjauhkan anda dari padanya; jika kesusahan dan kesedihan menyebabkan kedukaan hati, maka yoga alat untuk melenyapkannya, yoga adalah pengekangan kecenderungan rasa hati, penahanan kehendak hati; orang yang menguasai itu semua disebut pandita.

Selanjutnya mengenai kata Guru itu sendiri, Guru Gita sloka 40 menyebutkan:

Gukarascandhakarasca rukarastannirodhakrt, andhakaravinasitvad gururityabhidhiyate.

Terjemahannya:

$\mathrm{Gu}$ adalah kegelapan, $\mathrm{Ru}$ adalah penghilangnya, karena orang yang menghilangkan kegelapan, disebut Guru.

Berdasarkan sloka tersebut, maka yang dimaksud dengan guru adalah orang yang memiliki kewajiban atau mampu memberikan penerangan dalam hati, diri, dan kehidupan manusia. Penerangan dalam hal ini sudah tentu adalah penerangan berupa kecemerlangan ilmu pengetahuan (Vidya) yang akan melenyapkan kegelapan hati dan pikiran manusia (Avidya). Manusia diselimuti oleh kebodohan, yang menyebabkan ia terjerumus dalam kegelapan. Ia tak mampu berpikir dengan jernih karena tak memiliki pengetahuan, ia melakukan halhal yang tidak pantas karena terkekang oleh kebodohan dan nafsu, dalam hal ini hanya pengetahuanlah yang mampu menyelamatkan diri dan kehidupan manusia. Pengetahuan itu dalam konteks ini hanya bisa diperoleh dari sang guru. Berdasarkan uraian tersebut jadi jelaslah 
bahwasanya apapun istilahnya atau sebutannya, guru itu memiliki tugas dan kewajiban yang sangat utama dan mulia.

\section{Pupuh}

Pupuh adalah bentuk lagu yang terikat oleh pada lingsa. Pada artinya banyak bilangan suku kata dalam satu kalimat atau carik (koma), dan lingsa artinya perubahan-perubahan suara (a, i, u, e, o) pada suku kalimat yang terakhir (Sugriwa, 1978:3). Penggunaan pupuh dalam Gaguritan Dharma Prawerti dapat diuraikan sebagai berikut:

1. PupuhPucung

Pupuh Pucung dalam satu bait terdiri dari 6 baris, dimana pada lingsa dalam satu bait pupuh pucung adalah $4 \mathrm{u}, 8 \mathrm{u}, 6 \mathrm{a}$, $8 \mathrm{i}, 4 \mathrm{u}$, dan 8a. Pupuh pucung I digunakan pada bait 1 sampai dengan bait 18 (GDP hal 3-4), dan pupuh pucung II digunakan pada bait 1 sampai dengan 20 (GDP hal 16-17).

2 Pupuh Ginanti

Pupuh Ginanti dalam satu bait terdiri dari 6 baris, dimana pada lingsa dalam satu bait pupuh Ginanti adalah 8u, 8i, 8a, 8i, 8a, dan 8i. Pupuh Ginanti I digunakan pada bait 1 sampai dengan bait 30 (GDP hal 4-7).

3. Pupuh Ginada

Pupuh Ginada dalam satu bait terdiri dari 7 baris, dimana pada lingsa dalam satu bait pupuh Ginada adalah 8a, 8i, 8a/ o, 8u, 8a, 4i dan 8a. Pupuh Ginada digunakan pada bait 1 sampai dengan bait 22 (GDP hal 7-10).

4. Pupuh Sinom

Pupuh Sinom dalam satu bait terdiri dari 10 baris, dimana pada lingsa dalam satu bait pupuh Sinom adalah 8a, 8i, 8a, 8i, 8i, 8u, 8a, 8i, 4u dan 8a. Pupuh Sinom I digunakan pada bait 1 sampai dengan bait 36 (GDP hal 10-15), Pupuh SInom II digunakan pada bait 1 sampai dengan bait 23 (GDP hal 22-25), Pupuh Sinom III digunakan pada bait 1 sampai dengan bait 13 (GDP hal 28-30), dan Pupuh Sinom IV digunakan pada bait 1 sampai dengan bait 21 (GDP hal 40-43).

5. PupuhDurma

Pupuh Durma dalam satu bait terdiri dari 7 baris, dimana pada lingsa dalam satu bait pupuh Durma adalah 12a, 8i, 6a, 8a, 8i, 4a,dan 8i. Pupuh Durma digunakan pada bait 1 sampai dengan bait 35 (GDP hal 18-22).

6. PupuhAdri

Pupuh Adri dalam satu bait terdiri dari 9 baris, dimana pada lingsa dalam satu bait pupuh Adri adalah 10a, 6a/e, 8i, 8u, 8u, 8e, 8u, 8a,dan 8a. Pupuh Adri I digunakan pada bait 1 sampai dengan bait 21 (GDP hal 25-28), pupuh Adri II digunakan pada bait 1 sampai dengan bait 25 (GDP hal 36-39).

7. Pupuh Pangkur

Pupuh Pangkur dalam satu bait terdiri dari 9 baris, dimana pada lingsa dalam satu bait pupuh Pangkur adalah 8a, 12i, 8u, 8a, 12u, 8a,dan 8a. Pupuh Pangkur digunakan pada bait 1 sampai dengan bait 23 (GDP hal 30-33).

8. Pupuh Maskumambang

Pupuh Maskumambang dalam satu bait terdiri dari 4 baris, dimana pada lingsa dalam satu bait pupuh Maskumambang adalah 12i, 6a, 8u, dan 8a. Pupuh Maskumambang digunakan pada bait 1 sampai dengan bait 7 (GDP hal 34).

9. Pupuh Smarandana

Pupuh Smarandana dalam satu bait terdiri dari 7 baris, dimana pada lingsa dalam satu bait pupuh Smarandana adalah 8i, 8a, 8i, 8a, 8a, 8u, 8a. Pupuh Smarandana digunakan pada bait 1 sampai dengan bait 12 (GDP hal 34-36). 


\section{Ajaran Kesusilaan yang Terdapat dalam Gaguritan Dharma Prawerti}

Setelah menyimak isi dari Gaguritan

Dharma Prawerti, dapatlah sekiranya dikemukakan bahwasanya Gaguritan Dharma Prawerti termasuk karya seni di bidang sastra yang tergolong baru yang ditulis pada tahun 1971 oleh Ida Pedanda Putra Kamenuh. Gaguritan Dharma Prawerti mengandung begitu banyak ajaran-ajaran kesusilaan yang bersumber dari ajaran-ajaran agama Hindu. Gaguritan Dharma Prawerti menjadi sebuah media yang tepat untuk menyampaikan ajaranajaran kesusilaan tersebut. Ajaran kesusilaan sangat dibutuhkan dalam kehidupan manusia, mengingat dalam kehidupan yang penuh interaksi antar manusia norma dan etikaitu mutlak dijadikan kontrol perilaku.

Sudarsono (2008:188) menjelaskan bahwa etika adalah ilmu yang membahas perbuatan baik dan perbuatan buruk manusia sejauh yang dapat dipahami oleh pikiran manusia. Senada dengan hal itu Salam (1997:3) menjelaskan bahwa etika bermakud membantu manusia untuk bertindak secara bebas dan dapat dipertanggungjawabkan, karena setiap tindakannya selalu lahir dari keputusan pribadi yang bebas dengan selalu bersedia untuk mempertanggungjawabkan tindakannya itu karena memang ada alasan-alasan dan pertimbangan-pertimbangan yang kuat mengapa ia bertindak seperti itu.

Ajaran kesusilaan agama Hindu yang termuat dalam Gaguritan Dharma Prawerti mengajarkan kepada setiap orang agar hendaknya senantiasa menjadikan ajaranajaran kesusilaan itu sebagai pedoman dalam setiap perilakunya sehingga dapat diwujudkan kehidupan yang aman tenteram dan damai.

Sekiranya dapat dinyatakan bahwa ajaranajaran kesusilaan agama Hindu yang terdapat dalam Gaguritan Dharma Prawerti menginginkan agar umat Hindu senantiasa tidak membunuh atau menyakiti, boleh memotong hewan jika untuk upacara yadnya, mengasihi semua makhluk, tidak berkata-kata keras atau tajam (menghardik), tidak berucap yang menyakitkan hati, tidak melakukan perbuatan yang menyebabkan celaka, teguh memegang ajaran kesusilaan, selalu dekat dengan sang guru (berbhakti), menyerahkan diri sepenuhnya pada sang guru, bersikap tenang, bersih, tulus dan suci, selalu waspada, bersemangat, tidak suka berbohong, jujur dalam setiap perkataan, setia dan patuh kepada perintah sang guru, memegang teguh ajaran kebenaran, selalu mengupayakan ketentraman dan kedamaian, mampu menyatukan antara pemikiran, perasaan, dan perbuatan, sadar dengan keadaan diri sendiri (tahu diri), selalu menjalin hubungan baik dengan orang lain, memandang bahwa setiap manusia punya derajat yang sama, tidak berbuat jahat, tidak mencuri, tidak berpura-pura baik, tidak suka bermusuhan dan membuat rusuh, suka akan ketertiban, bersikap tenang dalam batin dan juga dalam perbuatan, tidak lekas marah apabila diejek, tidak lekas senang bila dipuji, bersikap teduh dan tenang bagaikan lentera yang tidak berasap dan bergoyang tertiup angin, senantiasa mengusahakan kerahayuan, selalu berbhakti kepada catur guru, selalu siap menjalankan perintah, sedia menyerahkan dirinya demi berbhakti kepada sang catur guru, tenang dan hening baik jasmani maupun rohani, tulus tanpa ada keinginan berlebihan (loba), tiada iri hati, selalu menjaga kebersihan baik jasmani maupun rohani.

Selain itu Gaguritan Dharma Prawerti mengajarkan hendaknya manusia yang dalam hal ini adalah umat Hindu, untuk bisa mengendalikan diri dari setiap keinginan yang liar. Hal itu sendiri ditegaskan dalam sastra suci Bhagawadgita sebagai berikut:

Tasmat tvam indriyany adau niyamya bharatarsabha, papmanam prajahi hy enam jnana-vijnana-nasanam (BG III41). 
Terjemahannya:

Dari itu, pertama-tama kendalikanlah panca indramu dan basmilah nafsu yang penuh dosa, perusak segala pengetahuan dan kebijakan, wahai Arjuna yang baik.

Yogi yunjita satatam atmanam raharsi sthitah, ekaki yata-cittama nirasir aparigrahah (BG VI-10).

Terjemahannya:

Hendaknya seorang yogi selalu berusaha untuk memusatkan pikirannya di tempat terpencil sendirian, setelah menguasai pikiran dan raganya bebas dari nafsu keinginan dan kemilikan.

Prasanta manasam hy enam yoginam sukham uttamam, upaiti santa rajas am brahma-bhutam akalmasam (BG VI-27)

Terjemahannya:

Sesungguhnyakebahagiaan tertinggi dating pada yogi yang pikirannya tenteram damai, yang hawa nafsunya tiada lagi, tiada noda, bersatu denganBrahman.

Berdasarkan sloka-sloka Bhagawadgita diatas jelaslah bahwa segala kesengsaraan dan kedukaan berawal dari ketidakmampuan dalam mengendalikan nafsu keinginan yang pada dasarnya bersumber dari keinginan. SangArjuna sendiri berkata kepada Sri Krsna:

Cancalam hi manah krsna pramathi balavad drdham, tasyaham nigraham manye vayor iva su duskaram (BG VI34).

Terjemahannya:

Wahai Krsna, pikiran itu sungguh gelisah, bergejolak, kuat dank eras, dan sangat liar, kuat dan tak mudah dibelokkan karena sukar dikendalikan, seperti halnya mengendalikan angin.

Sungguhlah mudah berubah pikiran itu dan begitu cepat berubah. Ketidakmampuan mengendalikan pikiran akan mengarah pada nafsu keinginan yang mendorong manusia untuk memenuhinya. Dari sinilah sifat-sifat Asuri Sampad berupa Sadripu itu muncul. Nafsu keinginan (kama), rakus (lobha), bingung (moha), marah (krodha), mabuk (mada), dan iri hati (matsarya) akan semakin menenggelamkan manusia dalam kegelapan pikiran yang menjauhkannya dari kehidupan yang sejahtera, aman, tenteram, dan damai. Oleh karena itu sungguh penting untuk bisa mengendalikan pikiran, nafsu, dan keinginan agar tidak berlebih-lebihan terlebih lagi dalam kehidupan di jaman sekarang ini.

Terkait dengan hal itu, Gaguritan Dharma Prawerti yang berisikan ajaran-ajaran kesusilaan sungguh tepat dan relevan apabila digunakan sebagai sebuah pedoman dalam berperilaku. Kondisi masyarakat saat ini yang cenderung berperilaku hedonis, konsumtif, materialistis, dan pragmatis, bila tidak diimbangi dengan peneguhan ajaran-ajaran kesusilaan dalam diri setiap individu akan membawa masyarakat itu pada kehancuran dan kekacauan. Demikian sebabnya ajaran susila dalam agama harus senantiasaditegakkan.

\section{PENUTUP}

Berdasarkan pembahasan diatas maka dalam hal ini dapat disimpulkan bahwa Gaguritan Dharma Prawerti mengandung ajaran-ajaran susila agama Hindu yang sungguh tepat dijadikan pedoman dalam berperilaku dalam kehidupan sehari-hari demi terwujudnya kehidupan yang aman, tenteram, dan damai, yang dapat mendukung tercapainya kehidupan jagadhita seperti yang menjadi tujuan dalam agama Hindu sendiri.

Penulis menyarankan agar Gaguritan Dharma Prawerti dijadikan bacaan wajib khususnya dalam kegiatan Pasantian. Para pecinta sastra khususnya karya sastra dalam bentuk gaguritan akan memperoleh pengetahuan positif terkait dengan ajaran kesusilaan agama Hindu melalui pembacaan dan interpretasi Gaguritan Dharma Prawerti, 
sehingga sedikit tidaknya akan mampu menuntun setiap perilaku atau perbuatan untuk tetap berada di jalan yang benar dan tidak bertentangan dengan ajaran agama Hindu.

\section{DAFTAR PUSTAKA}

Arikunto, Suharsimi.1998. Prosedur Penelitian Suatu Pendekatan Praktek. Jakarta: Rineka Cipta

Donder, I Ketut. 2006. Sisya Sista Pedoman Menjadi Siswa Mulia. Surabaya: Paramita

Donder, I Ketut. 2008. Acarya Sista Pedoman Menjadi Guru dan Dosen Mulia. Surabaya: Paramita

Emzir. 2008. Metodologi Penelitian Pendidikan Kuantitatif dan Kualitatif. Jakarta: RajaGrafindo Persada

Hamidi. 2005. Metode Penelitian Kualitatif. Malang:UMM

Hardjana, AM. 1993. Penghayatan Agama. Yogyakarta: Kanisius

Hasan, Iqbal. 2002. Pokok-pokok Materi Penelitian dan Aplikasinya. Jakarta: Ghalia Indonesia
Hendropuspito, D. 2006. Sosiologi Agama. Yogyakarta: Kanisius

Huky, Wila. 1986. Pengantar Sosiologi. Surabaya: Usaha Nasional

Jalaluddin, H. 2002. Psikologi Agama. Jakarta: RajaGrafindo Persada

Kamenuh, Ida Pedanda Putra. Tt. Gaguritan Dharma Prawerti. Singaraja: Indra Jaya

Kutha Ratna, Nyoman. 2007. Estetika Sastra dan Budaya. Yogyakarta: Pustaka Pelajar

Maryaeni. 2008. Metode Penelitian Kebudayaan. Jakarta: Bumi Aksara

Medera, Nengah. 1997. Kakawin dan Mabebasan di Bali. Denpasar: Upada Sastra

Moleong, Lexy J. 2007. Metodologi Penelitian Kualitatif. Bandung: Remaja Rosdakarya

Narbuko, Cholid. 2005. Metodologi Penelitian. Jakarta: Bumi Aksara 
